\title{
Sección Especial - Invasiones Biológicas en Patagonia
}

\section{Integrando la Investigación y la Gestión de Especies Exóticas Invasoras en la Patagonia}

Las especies exóticas invasoras (EEI) son una de las causas del cambio ecológico global, afectando los ecosistemas nativos y la biodiversidad regional, produciendo pérdidas económicas y riesgos sanitarios. Si bien existen posiciones contrapuestas sobre la importancia de la biología de invasiones, poniéndose en duda los logros teóricos y prácticos de este campo científico, se propone que es una subdisciplina tan predictiva como la ecología misma y que las invasiones biológicas representan modelos importantes para poner a prueba hipótesis asociadas a la ecología de comunidades y ecosistemas. Por otra parte, para generar estrategias de manejo de las EEI es esencial no solo entender su biología y sus interacciones con el ecosistema invadido, sino también realizar investigación aplicada.

Pese al notable aumento de investigaciones sobre invasiones biológicas en Latinoamérica en las últimas décadas, todavía existen varios desafíos pendientes. En Patagonia, la información ecológica sobre EEI a distintos niveles es escasa o de acceso limitado. La tendencia actual de publicar las investigaciones en revistas científicas internacionales de alto factor de impacto, en lugar de favorecer revistas regionales y nacionales, podría incentivar prácticas científicas con efectos sociales y ecológicos negativos. En el caso de las EEI esto provoca que en muchos casos los gestores no tengan acceso a dicha información y por lo tanto no puedan aplicarla en acciones concretas. Por otro lado, es común que la información generada desde la gestión permanezca dentro de la literatura gris en informes técnicos de limitada divulgación. Esta realidad desfavorece el trabajo conjunto de gestores e investigadores en la co-producción de resultados, como el diseño de programas de manejo que combinen ciencia y acción para la toma de decisiones en conservación. En este sentido es vital generar alianzas entre la gestión y la investigación sobre EEI para mitigar sus impactos sobre los ecosistemas.

Para trabajar sobre estos desafíos, junto con la Dra. Laura Fasola (CADIC-CONICET), organizamos el Simposio "Invasiones en la Patagonia" durante la $25^{\circ}$ Reunión Argentina de Ecología con el objetivo de presentar distintos enfoques en el estudio de diferentes
EEI en Patagonia. Este espacio de trabajo proveyó la oportunidad de evaluar la realidad de los gestores y los investigadores y generar discusiones/reflexiones acerca de la necesidad de direccionar el avance del conocimiento para que los intereses académicos y de gestión encuentren un punto en común.

Esta Sección Especial de Ecología Austral trata de integrar el trabajo de investigadores y gestores como un modo de acortar la brecha entre ambos grupos, unificando publicaciones que abordan distintas temáticas relacionadas con la información requerida para el manejo de las EEI. Por lo tanto, los ejes temáticos de esta sección son los impactos de las EEI sobre el ecosistema nativo y las recomendaciones relacionadas con su gestión.

Cipriotti y colaboradores ejemplifican como el monitoreo a largo plazo es vital para el manejo de una EEI y presentan una serie de medidas de control que resultaron eficaces en reducir la cobertura de Hieracium pilosella en Patagonia Austral. Relva y Núñez exponen una síntesis de estudios para entender la invasión de pináceas, subrayando la complejidad de factores que la retrasan o facilitan, como la presencia de cérvidos invasores, para concluir delineando las implicancias de sus resultados en el manejo de la invasión. Villacide y colegas revisan los aspectos críticos que permitieron el éxito de la invasión de avispas exóticas en la Patagonia (como historia de vida, características ecológicas, acciones de manejo, etc.) y plantean nuevos desafíos para el manejo integrado de plagas. Macchi y Vigliano proveen una revisión sobre la importancia de la historia de introducciones y manejo de salmónidos en la región, destacando la relevancia socio-ecológica de esta invasión, donde no solo se deben tener en cuenta los impactos en los ecosistemas sino también la importancia económica de los salmónidos, y por lo tanto debe fomentarse un trabajo interdisciplinario e interjurisdiccional para el manejo de este recurso. Fasola y Valenzuela aplican directamente la teoría ecológica al manejo de carnívoros exóticos integrando la información científica para proponer una herramienta aplicada, enfocada en priorizar de áreas de manejo, y sugerir un protocolo de tareas de erradicación como estrategia para afrontar la problemática. Sanguinetti y colaboradores aportan su visión desde la 


\section{4}

gestión de las invasiones biológicas presentando resultados de distintas experiencias de manejo en jurisdicción de la Administración de Parques Nacionales, resumiendo logros, dificultades y desafíos a los que se enfrentan los tomadores de decisiones. Finalmente, Anderson y Valenzuela comparan las publicaciones científicas sobre invasiones biológicas con las opiniones y percepciones de los profesionales relacionados con las EEI en Argentina, para determinar la vinculación entre las investigaciones que se consideran prioritarias y las que efectivamente se llevan a cabo, presentando algunas consideraciones sobre posibles explicaciones y soluciones para la brecha encontrada entre "lo dicho y lo hecho".

Se espera que el conjunto de contribuciones que emanaron tanto del Simposio como de esta
Sección Especial sirvan para replantearnos el rol de los distintos actores sociales involucrados en una invasión biológica. Deberíamos profundizar el trabajo de manera interdisciplinaria en búsqueda de un objetivo común, incluyendo el manejo de las EEI desde un punto de vista integral y las investigaciones de sus dimensiones ecólógica y social.

El Comité Organizador de la Reunión Argentina de Ecología 2012 colaboró en la organización del Simposio. La organización OSARA financió parte de la participación de los expositores del evento. El equipo editorial de Ecología Austral acompañó la realización de esta Sección Especial y junto con los revisores mejoraron la propuesta de los autores logrando un producto que esperamos sea de interés de toda la comunidad.

Alejandro E. J. Valenzuela

Coordinación Patagonia Austral, Administración de Parques Nacionales

Universidad Nacional de Tierra del Fuego 